ISSN 0258-7122

Bangladesh J. Agril. Res. 38(3): 401-416, September 2013

\title{
FARMERS' PERCEPTION ABOUT VARIETY DEVELOPMENT AND ABIOTIC STRESSES ON POTATO CULTIVATION IN BANGLADESH
}

\author{
M. A. MONAYem MiaH ${ }^{1}$, T. M. B. Hossain ${ }^{1}$, S. Hossain $^{1}$ \\ M. S. KADIAN ${ }^{2}$ AND M. HOSSAIN ${ }^{3}$
}

\begin{abstract}
The socio-economic information on variety development and abiotic stresses of potato cultivation at farm level are scarce in Bangladesh. Therefore, an attempt was made to assess farmers' perceptions about variety development and different abiotic stresses on potato cultivation. Primary data were collected from 240 potato farmers of Bogra and Chittagong district. The study revealed that Granula, Cardinal, and Lalpakri were the most preferred potato varieties in Bogra, while Diamant and Dohazari were the dominant varieties in Chittagong. Most farmers $(70.87 \%)$ believe that the current potato yield $(21.5-22.67 \mathrm{t} / \mathrm{ha})$ can be further increased through introducing new HYVs. Drought and heat were two important limiting factors towards achieving the higher levels of potato yield. High yielding ability was considered as the most desirable varietal character and this was opined by almost $92.1 \%$ respondents, followed by drought resistant $(61.13 \%)$, proper late blight control $(58.75 \%)$, availability of adequate fund $(57.77 \%)$, heat tolerant $(53.60 \%)$, early maturity $(61.5 \%)$, and good demand $(44.5 \%)$ for HYV potatoes, whereas good test $(81.7 \%)$, higher price $(69.6 \%)$ and good storability $(65.2 \%)$ were reported for local varieties. Low yield, susceptible to diseases, late maturity and low demand were the reasons for abandoning some potato varieties in the past. Dohazari variety for Chittagong and Lalpakri for Bogra have higher levels of tolerance against abiotic stresses. Finally, early maturity followed by drought tolerance, heat tolerance, and salinity tolerance were important attributes farmers wanted in new potato varieties.
\end{abstract}

Keywords: Farmers' perception, variety development, abiotic stress, potato cultivation.

\section{Introduction}

Potato (Solanum tuberosum L.) is one of the most important food as well as vegetable crops in Bangladesh and is being cultivated throughout the country. Bangladesh ranked $11^{\text {th }}$ in the world in terms of potato production in 2008-09 (Hossain and Miah, 2010). In 2010-2011, about 8326.39 thousand metric tons of potatoes have been produced devoting 460.40 thousands hectares of land in

${ }^{1}$ Agricultural Economics Division, Bangladesh Agricultural Research Institute (BARI), Gazipur, Bangladesh. ${ }^{2}$ International Potato Center (CIP), Liaison Office, Pusa Campus, New Delhi, India, ${ }^{3}$ Tuber Crops Research Centre, BARI, Gazipur1701, Bangladesh. 
Bangladesh (BBS, 2011). The area and production of potatoes are increasing day by day due to its higher demand and profitability (Fig. 1). The annual growth rates of area, production, and yield of potato were estimated at $7.64 \%, 10.57 \%$, and $2.94 \%$ in the last decade (2002-2011), respectively (BBS, 2011).

Potato has multi-purpose uses and provides nutrients and plenty of carbohydrates. Since potato is consumed as a popular vegetable, it helps stabilize the vegetables market round the year through its adequate supply (Moazzem and Fujita, 2004). It is one of the productive crops that can play significant role in ensuring food security in Bangladesh since it can help to widen the food supply base and thereby help to minimize the risk of serious food shortages in the tropics and sub-tropics. Bangladesh Government has been trying to diversify food habits and encouraged potato consumption to reduce pressure on cereals especially on rice. So, potato is becoming an important food for ensuring food security in Bangladesh.

Fig 1. Area, production and yield of potato, 1990-09.

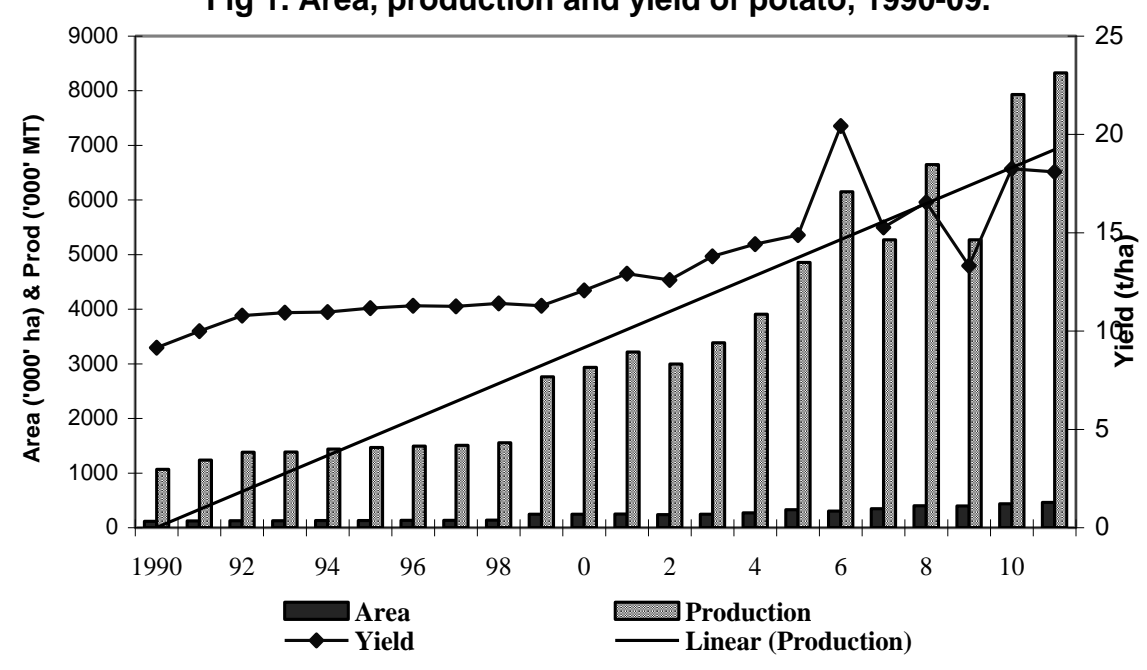

Climate change is now widely recognized as a phenomenon which is threatening for current way of life on the earth. During 2005, Bangladesh, India, and Pakistan faced temperatures $5-6^{\circ} \mathrm{C}$ above the regional average (UNDP, 2008). The average warming in annual temperature in the Himalaya and its vicinity between 1977 and 1994 was $0.06{ }^{\circ} \mathrm{C}$ per year (Shrestha et al., 1999). Climate related changes are observed in precipitation patterns, temperature, high intensity floods, cyclones, landslides, erosion, and increased sedimentation in Bangladesh. Therefore, it raises serious concerns for developing countries like 
Bangladesh with its tremendous social, environmental, and economic impacts. Intergovernmental Panel on Climate Change (IPCC) fourth assessment report mentions that climate change could decrease agricultural productivity in South Asia up to $30 \%$ by mid-21st century (IPCC, 2007).

Most farmers in Bangladesh produce potato at a subsistence level. They are also vulnerable to climate change since the production of potato is highly sensitive to various abiotic stresses including temperature and soil salinity. It is adversely affected by high temperature during tuber initiation (Basu and Minhas, 1991) and tuber bulking (Minhas and Devendra, 2005) stages. In India, potato production is estimated to fall during 2020 and 2050, respectively, by $19.65 \%$ and $44.90 \%$ in Karnataka; $18.23 \%$ and $31.77 \%$ in Gujarat; $13.02 \%$ and $24.59 \%$ in Maharashtra; and 9.65\% and 16.62\% in Madhya Pradesh (Singh et al., 2008). Many parts of Bangladesh, especially in Barind areas (drought prone) are also facing the problem of temperature fluctuation. Further, the saline areas of the country are also vulnerable to crop production including potato. So there is an urgent need to develop varieties suitable for growing under varied temperature and salinity. Developing heat, drought, and saline tolerant potato varieties will not only enhance production but may also extend its cultivation to non-traditional potato areas.

However, the socio-economic farm level information and farmers' perception on variety choice and abiotic stresses on potato cultivation are quite limited in Bangladesh which is very much important to the researchers and policy makers for the development of heat, drought, and saline tolerant potato varieties for attaining food security in the near future.It is also important to assess the nature and magnitude of farmers' awareness about the harmful impacts of future abiotic stresses in potato cultivation. Taking into consideration of all these facts, the present study was undertaken with the following objectives.

\section{Specific Objectives}

i. to find out the types of potato varieties using by the farmers and their farm level yields;

ii. to assess farmers' perceptions on variety development and abiotic stresses about potato cultivation;

iii. to recommend some policy guidelines for developing stress tolerant potato varieties. 


\section{Materials and Method}

Sampling technique: Multi-stages sampling technique was adopted to select sample respondents for the study. At the first stage, two potato growing districts, namely Bogra and Chittagong were selected purposively. Bogra district represents the drought prone areas, whereas Chittagong district represents the heat and saline areas of Bangladesh. In the second stage, four Upazilas from Bogra district and two Upazilas from Chittagong district were also purposively selected consulting with both local extension personnel and potato scientists. Considering the resource limitations, only two Upazilas from Chittagong district were selected. In the third stage, one agricultural block from each selected Upazila was selected for household survey. In the final stage of sampling, a total of 240 potato farmers ( 6 blocks x 40 samples), taking 40 farmers from each block were chosen from the list of potato growers following simple random sampling method irrespective of farm category for interview.

Method of data collection: A pre-tested interview schedule was used to collect primary data and information from potato farmers during October 2010. Relevant information of the studied Upazilas were obtained from local DAE offices. A team of experienced scientists and trained enumerators collected primary data and information through interviewing the sampled potato farmers.

Analytical technique: The collected data were edited, summarized, and analyzed based on various categories of potato farmers i.e. marginal (cultivated area 0.202$0.603 \mathrm{ha}$ ), small (cultivated area 0.607-1.008 ha), medium (cultivated area 1.012$3.032 \mathrm{ha}$ ), and large (cultivated area $>3.036 \mathrm{ha}$ ). In most cases, simple descriptive statistics and accounting methods were adopted to analyze the collected data.

\section{Results and Discussion}

Farm level use of potato varieties: Both modern and indigenous potato varieties are being cultivated in the study areas. However, substantial dissimilarity of using potato varieties was observed in Bogra and Chittagong. In Bogra, the highly adopted varieties were Granula, Cardinal, Diamant, Ruma, and Lalpakri, whereas Diamant and Dohazari varieties were found to me in Chittagong areas. In the case of HYV, the highest percentage of farmers in all categories $(59.6 \%)$ cultivated Granula variety followed by Cardinal and Diamant. On the other side, nearly $40 \%$ farmers used Lalpakri and $33.3 \%$ farmers used Dohazari as indigenous potato varieties (Table 1).

Variety-wise potato yield: The productivity of potato depends on many factors, such as varietal character, use of appropriate amount of inputs, intercultural 
operations, disease and insect-pest management, and local weather variables. Change in any factors results in the change of potato yield. Area and variety-wise potato yields are presented in Table 2 .

Table 1. Farmers' adoption practices of potato varieties in the study areas.

\begin{tabular}{|c|c|c|c|c|c|}
\hline \multirow{2}{*}{ Variety cultivated } & \multicolumn{4}{|c|}{ Farmers' category } & \multirow{2}{*}{$\begin{array}{c}\text { All } \\
\text { category }\end{array}$} \\
\hline & Marginal & Small & Medium & Large & \\
\hline No. of respondents & $n=16$ & $n=136$ & $n=78$ & $n=10$ & $n=240$ \\
\hline \multicolumn{6}{|l|}{ 1. High yielding variety } \\
\hline Granula & 37.5 & 55.9 & 67.9 & 80.0 & 59.6 \\
\hline Cardinal & 6.25 & 18.4 & 25.6 & 30.0 & 20.4 \\
\hline Diamant & -- & 8.8 & 14.1 & 10.0 & 10.0 \\
\hline Others $^{1}$ & -- & 3.7 & 2.6 & 10.0 & 3.3 \\
\hline \multicolumn{6}{|l|}{ 2. Indigenous variety } \\
\hline Ruma & -- & 7.4 & 11.5 & 10.0 & 8.3 \\
\hline Lal pakri & 37.5 & 36.8 & 42.3 & 60.0 & 39.6 \\
\hline Fata pakri & -- & 16.9 & 11.5 & 10.0 & 13.8 \\
\hline Bot pakri & -- & 1.5 & 7.7 & -- & 3.3 \\
\hline Dohazari & 43.8 & 33.1 & 33.3 & 20.0 & 33.3 \\
\hline Others $^{2}$ & -- & 8.1 & 23.1 & -- & 12.1 \\
\hline
\end{tabular}

${ }^{1}$ Patronis, Alvira \& Asterisk variety; ${ }^{2}$ Tel pakri \& Lolit variety

The average yield of HYV potato was higher than that of local variety. In 2009-2010, the average per hectare yield was estimated at 22.67 for Granula, 21.50 for Diamant, and 22.57 for Cardinal. On the other hand, the average per hectare yield of local variety was 16.74 for Ruma, 15.312 for Pakri, and 16.27 for Dohazari. It was observed that the average yields of HYV and local variety potatoes in 2008-2009 were much lower compared to the yields observed in 2009-2010 (Table 2). The main reason behind this lower yield was opined to be bad weather, especially the occurrence of drought. However, the average national yield was 13.06 tons per hectare during 2008-2009 (BBS, 2009).

\section{Farmers' perceptions on variety development}

Yield enhancing attributes: An attempt was made to analyze farmers' opinions on whether potato yield on their farms could be increased and results have been presented in Table 3. A total of nineteen factors relating to crop management and enabling environment, which can contribute towards increasing the yield of potato were analyzed. All the respondent farmers believe that it is possible to increase the yield of potato. The highest proportions of farmers $(70.87 \%)$ believe 
that the current potato yield can be further increased through introducing new high yielding potato varieties. Other closely perceived factors were drought resistant potato varieties $(61.13 \%)$ followed by proper late blight control $(58.75 \%)$, availability of adequate fund $(57.77 \%)$, heat tolerant variety $(53.60 \%)$, training on potato cultivation $(52.23 \%)$, and adequate quantity and timely availability of fertilizers $(50.45 \%)$. Importance index of these factors, ranging from 1 (low) to 5 (high) was the highest for high yielding new potato varieties (3.11) followed by drought resistant potato varieties (2.23), availability of adequate fund (2.28), adequate quantity and timely availability of fertilizers (2.13), etc.

Table 2. Yield (t/ha) of different potato varieties in the study areas.

\begin{tabular}{lccccc|c}
\hline \multirow{2}{*}{ Year } & \multicolumn{5}{c|}{ Farmers' category } & \multirow{2}{*}{ All category } \\
\cline { 2 - 5 } & Marginal & Small & Medium & Large & \\
\hline A. High Yielding Variety & & & & & \\
Granula & $n=6$ & $n=76$ & $n=53$ & $n=8$ & $n=143$ \\
$\quad 19.437$ & 17.613 & 14.582 & 18.067 & 16.750 \\
$\quad 2008-2009$ & 20.924 & 22.907 & 22.528 & 22.654 & 22.669 \\
Diamant & $n=0$ & $n=12$ & $n=11$ & $n=1$ & $n=24$ \\
$2008-2009$ & -- & 15.167 & 15.259 & 17.414 & 15.400 \\
$2009-2010$ & -- & 21.383 & 21.398 & 23.952 & 21.497 \\
Cardinal & $n=1$ & $n=25$ & $n=20$ & $n=3$ & $n=49$ \\
$2008-2009$ & 8.347 & 16.759 & 13.485 & 14.733 & 14.888 \\
$2009-2010$ & 20.441 & 22.406 & 22.679 & 23.886 & 22.568 \\
B. Local variety & & & & & \\
$\quad$ Ruma & $n=0$ & $n=10$ & $n=9$ & $n=1$ & $n=20$ \\
$2008-2009$ & -- & 13.628 & 17.964 & -- & 15.796 \\
$2009-2010$ & -- & 16.444 & 17.109 & 16.467 & 16.744 \\
$\quad$ Pakri* & $n=6$ & $n=75$ & $n=48$ & $n=7$ & $n=136$ \\
$2008-2009$ & 12.707 & 12.457 & 11.009 & 11.514 & 11.929 \\
$2009-2010$ & 15.885 & 15.253 & 15.256 & 15.907 & 15.312 \\
$\quad$ Dohazari & $n=7$ & $n=45$ & $n=26$ & $n=2$ & $n=80$ \\
$2008-2009$ & 13.464 & 12.312 & 12.373 & 11.718 & 12.418 \\
$2009-2010$ & -- & 16.686 & 16.071 & 14.408 & 16.266 \\
\hline
\end{tabular}

* Pakri variety includes Lalpakri, Fatapakri and Botpakri

The analysis also reveals that marginal farmers put higher stress on having adequate availability of fund and new high yielding varieties. Both medium and large category farmers put the highest emphasis on having drought tolerant potato varieties and proper late blight control (Table 3). 
Table 3. Farmers' perceptions about potato yield increasing factors (multiple responses)

\begin{tabular}{|c|c|c|c|c|c|c|c|c|c|c|}
\hline \multirow{3}{*}{$\begin{array}{c}\text { Factors of increasing } \\
\text { yield }\end{array}$} & \multicolumn{8}{|c|}{ Farmers' Category } & \multirow{2}{*}{\multicolumn{2}{|c|}{ All category }} \\
\hline & \multicolumn{2}{|c|}{ Marginal farmer } & \multicolumn{2}{|c|}{ Small farmer } & \multicolumn{2}{|c|}{ Medium farmer } & \multicolumn{2}{|c|}{ Large farmer } & & \\
\hline & $\begin{array}{c}\% \\
\text { responded } \\
\end{array}$ & \begin{tabular}{|c|} 
Impor- \\
tance
\end{tabular} & $\begin{array}{c}\% \\
\text { responded }\end{array}$ & \begin{tabular}{|c|} 
Impor- \\
tance
\end{tabular} & $\begin{array}{c}\% \\
\text { responded }\end{array}$ & \begin{tabular}{|c} 
Impor- \\
tance
\end{tabular} & $\begin{array}{c}\% \\
\text { responded }\end{array}$ & \begin{tabular}{|c} 
Impor- \\
tance
\end{tabular} & $\%$ responded & $\begin{array}{r}\text { Impor- } \\
\text { tance }\end{array}$ \\
\hline $\begin{array}{l}\text { Yield can further } \\
\text { increase }\end{array}$ & 100 & - & 100 & -- & 100 & -- & 100 & -- & 100 & -- \\
\hline $\begin{array}{l}\text { 1. Timely and sufficient } \\
\text { irrigation water }\end{array}$ & 56.58 & 1.84 & 46.44 & 1.50 & 47.43 & 1.63 & 43.33 & 1.53 & 46.52 & 1.55 \\
\hline $\begin{array}{l}\text { 2. Soil reclamation (for } \\
\text { alkaline/saline/too } \\
\text { acidic) }\end{array}$ & 13.10 & 0.36 & 17.19 & 0.72 & 18.79 & 0.74 & -- & -- & 16.82 & 0.68 \\
\hline $\begin{array}{l}\text { 3. High yielding potato } \\
\text { varieties }\end{array}$ & 86.90 & 3.82 & 71.04 & 3.07 & 70.49 & 2.84 & 80.00 & 2.93 & 70.87 & 3.11 \\
\hline $\begin{array}{l}\text { 4. Drought resistant/ } \\
\text { tolerant potato } \\
\text { varieties }\end{array}$ & 48.25 & 1.91 & 58.70 & 2.22 & 72.65 & 2.68 & 70.00 & 2.67 & 61.13 & 2.34 \\
\hline $\begin{array}{l}\text { 5. Heat tolerant potato } \\
\text { varieties }\end{array}$ & 61.34 & 2.12 & 57.04 & 2.04 & 49.54 & 1.69 & 56.67 & 1.83 & 53.60 & 1.94 \\
\hline 6. Salinity tolerance & 44.68 & 1.15 & 31.99 & 0.54 & 27.80 & 0.68 & 46.67 & 0.70 & 31.97 & 0.66 \\
\hline $\begin{array}{l}\text { 7. Higher doses of } \\
\text { fertilizers }\end{array}$ & 8.33 & 0.20 & 24.35 & 0.98 & 17.93 & 0.78 & 6.67 & 0.07 & 20.12 & 0.85 \\
\hline 8. Proper weed control & 13.10 & 0.41 & 9.35 & 0.31 & 12.79 & 0.42 & 23.33 & 0.93 & 11.13 & 0.37 \\
\hline $\begin{array}{l}\text { 9. Right insect/ pest } \\
\text { control }\end{array}$ & 17.30 & 0.61 & 25.51 & 0.81 & 33.35 & 1.18 & 30.00 & 1.20 & 27.23 & 0.92 \\
\hline
\end{tabular}




\begin{tabular}{|c|c|c|c|c|c|c|c|c|c|c|}
\hline $\begin{array}{l}\text { 10. Right late blight } \\
\text { disease management }\end{array}$ & 65.48 & 2.50 & 58.27 & 2.11 & 60.23 & 2.12 & 80.00 & 3.43 & 58.75 & 2.13 \\
\hline $\begin{array}{l}\text { 11. Right control of } \\
\text { other diseases }\end{array}$ & 30.95 & 1.12 & 33.21 & 1.13 & 33.77 & 1.14 & 23.33 & 0.93 & 32.77 & 1.14 \\
\hline $\begin{array}{l}\text { 12. Right quality and } \\
\text { timely availability of } \\
\text { pesticides }\end{array}$ & 52.38 & 1.87 & 37.59 & 1.34 & 47.88 & 1.66 & 56.67 & 1.80 & 41.40 & 1.53 \\
\hline $\begin{array}{l}\text { 14. Right quality and } \\
\text { timely availability of } \\
\text { seed }\end{array}$ & 34.52 & 1.68 & 44.46 & 1.81 & 54.68 & 2.34 & 56.67 & 2.33 & 46.10 & 1.98 \\
\hline $\begin{array}{l}\text { 15. Availability of } \\
\text { adequate funds }\end{array}$ & 82.14 & 3.60 & 59.93 & 2.27 & 53.02 & 1.95 & 43.33 & 1.90 & 57.77 & 2.28 \\
\hline $\begin{array}{l}\text { 18. Keep potato in the } \\
\text { field for long time }\end{array}$ & 13.10 & 0.59 & 1.93 & 0.07 & 7.70 & 0.20 & 6.67 & 0.13 & 4.58 & 0.10 \\
\hline $\begin{array}{l}\text { 19. Training on potato } \\
\text { cultivation }\end{array}$ & 60.15 & 2.06 & 53.99 & 1.70 & 53.44 & 1.75 & 20.00 & 0.67 & 52.23 & 1.72 \\
\hline
\end{tabular}


Table 4. Farmers' responses on desirable and undesirable qualities of different potato varieties.

(\% farmers responded)

\begin{tabular}{|c|c|c|c|c|c|c|c|c|c|}
\hline \multirow[b]{2}{*}{ Type of quality } & \multicolumn{4}{|c|}{ High Yielding Variety (HYV) } & \multicolumn{5}{|c|}{ Local Variety (LV) } \\
\hline & $\begin{array}{c}\text { Gran- } \\
\text { ula }\end{array}$ & $\begin{array}{c}\text { Card- } \\
\text { inal }\end{array}$ & Dia-mant & $\begin{array}{c}\text { All } \\
\text { HYV }\end{array}$ & Ruma & $\begin{array}{c}\text { Lal } \\
\text { pakri }\end{array}$ & $\begin{array}{l}\text { Fata } \\
\text { pakri }\end{array}$ & $\begin{array}{c}\text { Doha- } \\
\text { zari }\end{array}$ & $\begin{array}{l}\text { All } \\
\text { LV }\end{array}$ \\
\hline $\begin{array}{l}\text { No. of respondent } \\
\text { A. Good qualities }\end{array}$ & $n=126$ & $n=36$ & $n=51$ & $n=213$ & $n=22$ & $n=91$ & $n=37$ & $n=80$ & $n=230$ \\
\hline High yielding & 98.4 & 82.4 & 83.3 & 92.1 & 68.2 & 4.4 & 13.5 & 27.5 & 20.0 \\
\hline Good skin colour & 13.5 & 37.3 & 27.8 & 20.9 & 63.6 & 38.5 & 37.8 & 8.8 & 30.5 \\
\hline Heat tolerant & 3.2 & -- & -- & 1.9 & -- & 1.1 & 2.7 & -- & 0.9 \\
\hline Good tuber size & 39.7 & 23.5 & 30.6 & 34.8 & 31.8 & 2.2 & 8.1 & 2.5 & 6.1 \\
\hline Drought tolerant & 2.4 & -- & -- & 1.4 & -- & 11.0 & 16.2 & 12.5 & 11.3 \\
\hline Good storability & 4.0 & 7.8 & 8.3 & 5.7 & 9.1 & 69.2 & 67.6 & 75.0 & 65.2 \\
\hline Good demand/high price & 38.1 & 54.9 & 52.8 & 44.5 & 50.0 & 67.0 & 67.6 & 78.8 & 69.6 \\
\hline Good in taste & 3.2 & 54.9 & 33.3 & 19.1 & 13.6 & 94.5 & 78.4 & 87.5 & 81.7 \\
\hline Others & 5.6 & -- & -- & 3.3 & -- & 2.2 & -- & -- & 0.9 \\
\hline Susceptible to late blight & 24.6 & 35.3 & 27.8 & 27.2 & 36.4 & 29.7 & 35.1 & 43.8 & 36.1 \\
\hline Late maturing & -- & 15.7 & 8.3 & 4.6 & -- & 58.2 & 56.8 & 70.0 & 56.5 \\
\hline Bad tuber size & 2.4 & 5.9 & 11.1 & 5.1 & 22.7 & 61.5 & 81.1 & 53.8 & 58.3 \\
\hline Susceptible to drought & 12.7 & 11.8 & 13.9 & 12.8 & -- & 1.1 & -- & 2.5 & 1.3 \\
\hline Bad storability & 83.3 & 72.5 & 72.2 & 78.8 & 68.2 & 3.3 & 2.7 & -- & 8.3 \\
\hline Low demand/low price & 42.9 & 23.5 & 30.6 & 36.7 & 13.6 & -- & 2.7 & 2.5 & 2.6 \\
\hline Taste is not good & 92.9 & 33.3 & 47.2 & 71.9 & 50.0 & 1.1 & 2.7 & -- & 5.7 \\
\hline Others & 10.3 & 5.9 & 8.3 & 9.1 & 9.1 & 1.1 & 5.4 & 2.5 & 3.0 \\
\hline
\end{tabular}


Table 5. Farmers' reasons for rejecting of potato varietals (multiple responses).

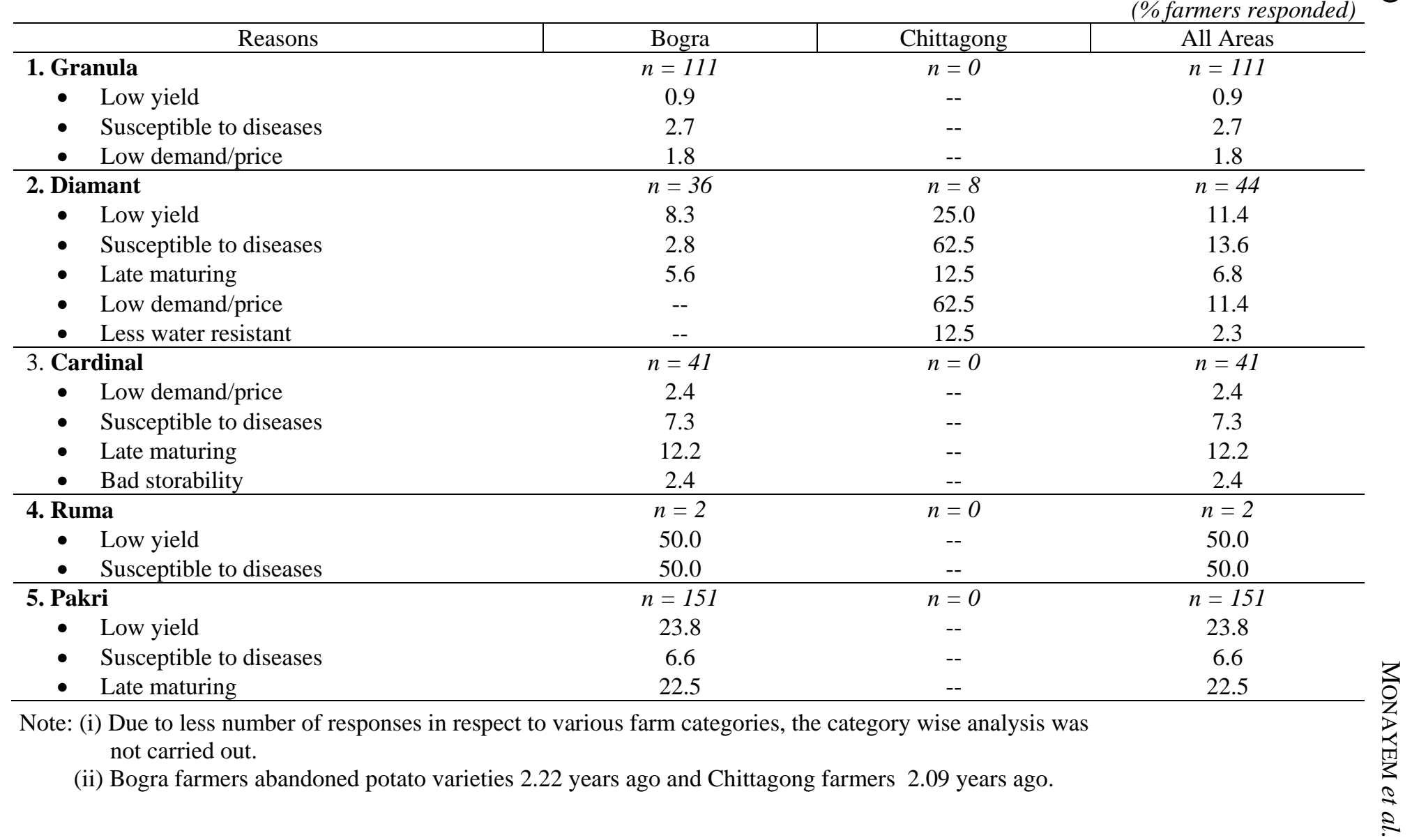


Good and bad varietal characters: Potato farmers were found to grow different types of HYVs and indigenous potato varieties in the study areas. They were asked to name three most important good and bad characters of their cultivated potato varieties. In the case of HYV potato, the highest desirable varietal character was high yield $(92.1 \%)$ followed by early maturity $(61.5 \%)$, good demand/price (44.5\%), and desirable tuber size (34.8\%). On the other hand, good test $(81.7 \%)$, higher price (69.6\%), good storability (65.2\%), and good colour $(30.5 \%)$ were important desirable characters of the local variety (Table 4).

Respondent farmers also mentioned undesirable qualities of their cultivated varieties. The highest proportion of farmers $(78.8 \%)$ opined that poor storability was the worst character of HYV potato, which was followed by bad taste (71.9\%), low price (36.7\%), and susceptible to late blight (27.2\%). For local variety, the undesirable characters were reported to be low yield (75.2\%), bad tuber size (58.3\%), late maturity (56.5\%), and susceptible to late blight (36.1\%).

Reasons for abandoning varieties: Due to some negative perceptions, some respondent farmers in Bogra district abandoned five potato varieties comprising three HYVs and two local varieties. On the other hand, farmers in Chittagong so far abandoned only one variety. Low yield and susceptible to diseases were reported to be common reasons for abandoning these varieties as shown in Table 5. Late maturity was another important reason for which some farmers in all study areas abandoned Diamant, Cardinal, and Pakri varieties. Low demand/price was reported to be a vital reason for abandoning Diamant variety in Chittagong district. It is important to state that the potato varieties those were abandoned by some responding farmers are still popular and widely cultivated varieties in the study areas.

\section{Farmers' perceptions on abiotic stresses}

Preference of potato varieties: Respondent farmers were asked to give preference on the four available future potato varieties against abiotic stresses. The likely future varieties will be heat tolerant, drought tolerant, saline tolerant and early bulking in nature. Respondent's preferences were analyzed and presented in Table 6. It was observed that the farmers of all categories showed very high level of preference (score 4.46) toward the variety having early maturing character. Among the three characters of abiotic stresses, respondent farmers expressed the highest level of preference (score 3.58) for drought tolerant variety followed by heat tolerant (score 2.85) and saline tolerant variety (score 1.49) in the near future. 
Table 6. Level of preference of potato varieties against abiotic stresses in the near future.

\begin{tabular}{l|c|c|c|c|c}
\hline \multirow{2}{*}{ Varietal quality } & \multicolumn{4}{|c|}{ Farmers' category } & \multirow{2}{*}{$\begin{array}{c}\text { All } \\
\text { category }\end{array}$} \\
\cline { 2 - 5 } & Marginal & Small & Medium & Large & $n=240$ \\
$\begin{array}{l}\text { No. of } \\
\text { respondents }\end{array}$ & $n=16$ & $n=136$ & $n=78$ & $n=10$ & $n$ \\
Heat tolerant & 3.38 & 2.88 & 2.65 & 3.30 & 2.85 \\
Drought tolerant & 3.69 & 3.63 & 3.47 & 3.60 & 3.58 \\
Saline tolerant & 1.56 & 1.56 & 1.33 & 1.70 & 1.49 \\
Early maturing & 4.31 & 4.50 & 4.45 & 4.20 & 4.46 \\
\hline
\end{tabular}

Note: Level of preference (range 1 to 5 ): Very low =1; Low = 2; Medium = 3; High = 4; Very high $=5$

Response on abiotic stresses: Heat, drought, and salinity are very important abiotic stresses for crop production. With exposure to higher temperature, potato plants show increase vegetative growth without converting carbohydrates into tubers (Minhas and Devendra, 2005). Drought is responsible in general disturbance in plant health. Plant becomes weak and more susceptible to other biotic and abiotic stresses. The higher level of salinity in the soil is also detrimental to potato cultivation.

Bogra District represents the drought area and Chittagong district represents the heat and saline areas of Bangladesh. Respondent farmers faced to some extent these abiotic stresses during potato production. Therefore, potato farmers were asked to express their opinions on these three abiotic stresses. The respondent farmers in all categories believed that drought and heat were important two limiting factors towards achieving the higher levels of yield (Table 7). A lower proportion (score 2) of respondents pointed out salinity as abiotic stress to the potato crop. However, the higher proportion of marginal and small farmers regarded drought as a potential threat to their potato crop. Since ground water level was reported to be decreasing year after year in the study areas, the cost of digging tube wells will be very high in the near future.

Respondent farmers were also interviewed to give their perceptions on the abiotic tolerance capacity of their cultivated potato varieties. In this respect, they pointed out two local varieties namely Dohazari for Chittagong district and Lalpakri for Bogra district which have higher levels of tolerance against abiotic stresses compared to other local and HYV potatoes. Cardinal and Diamant varieties were reported to be more or less similar level of tolerance against (score 2) abiotic stresses (Table 8). 
Table 7. Farmers' perceived relative importance of abiotic stresses on potato production.

\begin{tabular}{l|c|c|c|c|c}
\hline \multirow{2}{*}{ Abiotic stress } & \multicolumn{3}{|c|}{ Farmers' category/Priority level } & \multirow{2}{*}{ All category } \\
\cline { 2 - 5 } & Marginal & Small & Medium & Large & \\
\hline A. Bogra & $n=9$ & $n=91$ & $n=52$ & $n=8$ & $n=160$ \\
Draught & 4.33 & 3.84 & 3.65 & 3.63 & 3.79 \\
Heat & 3.00 & 3.10 & 2.90 & 3.25 & 3.04 \\
Salinity & 1.00 & 1.00 & 1.00 & 1.50 & 1.05 \\
B. Chittagong & $n=7$ & $n=45$ & $n=26$ & $n=2$ & $n=80$ \\
Draught & 3.14 & 3.22 & 3.23 & 3.50 & 3.23 \\
Heat & 3.43 & 2.93 & 2.77 & 4.50 & 2.96 \\
Salinity & 2.67 & 2.50 & 2.67 & 2.00 & 2.55 \\
C. All Areas & $n=16$ & $n=136$ & $n=78$ & $n=10$ & $n=240$ \\
Draught & 3.81 & 3.63 & 3.51 & 3.60 & 3.60 \\
Heat & 3.19 & 3.04 & 2.86 & 3.50 & 3.01 \\
Salinity & 2.25 & 2.03 & 2.25 & 1.67 & 2.08 \\
\hline
\end{tabular}

Note: Level of priorities (range 1 to 5): 1= very low, 2= Low, 3= Medium, 4= High, and $5=$ Very high

Table 8. Level of abiotic stress tolerances of different potato varieties as perceived by the sample farmers.

\begin{tabular}{l|c|c|c|c|c}
\hline \multirow{2}{*}{ Variety } & \multicolumn{3}{|c|}{ Farmers' category/Level of tolerance } & \multirow{2}{*}{ All category } \\
\cline { 2 - 5 } & Marginal & Small & Medium & Large & \\
\hline A. Bogra & $n=9$ & $n=91$ & $n=52$ & $n=8$ & $n=160$ \\
Granula & $2.0(3)$ & $2.0(22)$ & $2.0(17)$ & $2.5(4)$ & $2.1(46)$ \\
Cardinal & -- & $1.9(8)$ & $1.7(11)$ & $2.0(1)$ & $1.8(20)$ \\
Diamant & -- & $1.8(4)$ & $2.0(3)$ & $1.0(1)$ & $1.8(8)$ \\
Pakri & $1.0(3)$ & $1.5(32)$ & $1.3(29)$ & $1.5(4)$ & $1.4(68)$ \\
B. Chittagong & $n=7$ & $n=45$ & $n=26$ & $n=2$ & $n=80$ \\
Diamant & -- & $2.0(2)$ & $1.8(5)$ & $1.0(1)$ & $1.8(8)$ \\
Dohazari & -- & $1.0(2)$ & $1.2(5)$ & -- & $1.3(8)$ \\
Lolita & -- & $2.0(2)$ & $1.5(2)$ & -- & $1.7(3)$ \\
C. All Areas & $n=16$ & $n=136$ & $n=78$ & $n=10$ & $n=240$ \\
Granula & $2.0(3)$ & $2.0(22)$ & $2.2(17)$ & $2.5(4)$ & $2.1(46)$ \\
Cardinal & -- & $1.9(8)$ & $1.7(11)$ & $2.0(1)$ & $1.8(20)$ \\
Diamant & -- & $1.8(6)$ & $1.9(8)$ & $1.0(2)$ & $1.8(16)$ \\
Pakri & $1.0(3)$ & $1.5(32)$ & $1.3(29)$ & $1.5(4)$ & $1.4(68)$ \\
Dohazari & -- & $1.0(2)$ & $1.2(5)$ & $2.0(1)$ & $1.3(8)$ \\
Lolita & -- & $2.0(1)$ & $1.5(2)$ & -- & $1.7(3)$ \\
\hline
\end{tabular}

Note: Figures in the parentheses are number of respondents

Level of abiotic stresses tolerance (range 1 to 5):1= Very high, 2= High, 3= Medium, 4= Low, $5=$ Very low 


\section{Conclusion}

i. The highly used potato varieties were Granula, Cardinal, and Lalpakri in Bogra district, whereas Diamant and Dohazari were the preferred varieties in Chittagong areas. In 2009-2010, the yield of HYV potatoes ranged from 21.50 to $22.67 \mathrm{t} / \mathrm{ha}$, while the LVs, the yield range was 15.31 to $16.74 \mathrm{t} / \mathrm{ha}$. Most farmers believed that level of current potato yield could be uplifted through (a) introducing new high yielding potato varieties; (b) developing drought resistant varieties; (c) improving training on potato cultivation; (d) extending financial support; and (e) controlling late blight disease.

ii. The most desirable varietal characters of HYV potatoes were high yield, early maturity, and good market demand. Similarly, good test, higher price, and good storability were important characters for local variety.

iii. Low yield, susceptible to diseases, late maturity and low demand were the reasons for extinction of some potato varieties in the past.

iv. Among others, drought and heat were the two important factors causing lower yield of potato. Drought was, especially a potential threat for marginal and small farmers.

v. Dohazari variety for Chittagong and Lalpakri for Bogra has higher levels of tolerance against abiotic stresses. Besides, early maturity followed by drought tolerance, heat tolerance and salinity tolerance were the important attributes farmers wanted in new potato varieties.

\section{Policy Implications}

Development of abiotic stress tolerant varieties: Potato production is highly sensitive to various abiotic stresses including temperature and soil salinity. Development of heat, drought and saline tolerant varieties enhance potato production and extend its cultivation to non-traditional potato areas. Therefore, breeders should assign higher importance to develop abiotic stress tolerant potato varieties for combating future climate threats.

Development of early maturing varieties: T.aman-Potato-Boro is the dominant cropping pattern in Bogra district. Most farmers cultivate Boro rice after harvesting of potato. Therefore, they show very high level of preference toward the variety having early maturing character. So breeders should give much emphasis to develop a number of early maturing potato varieties having late blight resistant character.

Development of new varieties having better storability: Most small and marginal farmers have poor access to cold storage facility due to small quantity of produces and financial inability. They have to sell their potatoes to middlemen immediately after harvesting with lower price. Therefore, development of new 
varieties having better storability at home condition will be highly beneficial to the poor potato farmers.

Availability of irrigation water: Higher proportion of marginal and small farmers considered drought and heat to be potential threat for their future potato crops. In the study area entire irrigation is through DTW and STW. They have to buy water from others since digging tube well needs higher cost. Besides, irrigation charge is very high and sometimes unavailable when required. Therefore, the government should encourage cooperative tube wells through establishing self help groups of the farmers providing them financial assistance.

Agricultural training: The farmers of all categories believe that their current potato yield can be further increased through providing training on production technologies. Therefore, the DAE should arrange and provide hand-on training for the potato farmers on production technologies on a regular basis.

Availability of seed and fertilizer: Majority of the farmers also perceived that their potato yield can be further increased through making seed and fertilizers timely available and inexpensive. So, the government should take appropriate steps to make these inputs available and economic to the farmers.

\section{Acknowledgement}

The authors are grateful to Md. Mohidul Hassan, Research Assistant, International Potato Centre (CIP), Liaison Office, Bangladesh; B. C. Kundu, Senior Scientific Officer, TCRC, BARI, Gazipur; Z. Ibragimov, Research Assistant, CIP, Liaison Office, 6 Osiyo street, Tashkent, Uzbekistan for collecting field level data through personal interview. The authors are also grateful to Niraj Sharma and S. Araya from CIP, Liaison Office, Pusa Campus, New Delhi, India for collecting field level data and various assistances regarding data analysis.

\section{References}

BBS. 2011. Year book of Agricultural Statistics. Bangladesh Bureau of Statistics, Statistics Division, Ministry of Planning, Government of the People's Republic of Bangladesh, Dhaka, Bangladesh.

Basu P. S. and J. S. Minhas. 1991. Heat tolerance and assimilate transport in different potato genotypes. Journal of Experimental Botany 42: 861-866.

Hossain, M. A. and M. A. M. Miah. 2010. Post-harvest losses and technical efficiency of potato storage systems in Bangladesh. Technical Report submitted to FAO Bangladesh. Available at: http://www.fao.org/inpho/content/conpend/text

IPCC. 2007. Climate Change 2007: Impacts, Adaptation and Vulnerability. Contribution of Working Group II to the Fourth Assessment Report of the IPCC, M.L. Parry, O.F. Canziani, J.P. Palutikof, P.J. van der Linden and C.E. Hanson (Eds.), Cambridge University Press, Cambridge, UK. 
Meyhuay, M. 2007. Potato: Post-harvest operations. Instituto de Desarrollo Agroindustrial (INDDA). http://www.fao.org/inpho/content/conpend/text/ ch17_02. htm\#TopOfPage

Miah, M. A. M., S. Hossain, T. M. B. Hossain, M. S. Rahman, M. M. Hassan, M. Hossain, B.C. Kundu, M. S. Kadian, N. Sharma, S. Araya, and Z. Ibragimov. 2011. Assessment of potato farmers' perceptions on abiotic stresses and implications for potato improvement research in Bbangladesh: a baseline survey. Research Report submitted to International Potato Centre (CIP), Liaison Office, Pusa Campus, New Delhi, India.

Minhas, J. S. and K. Devendra. 2005. Tuberization in heat tolerant hybrid HT/92-621 under controlled temperature conditions. Potato Journal 32: 195-196.

Moazzem, K. G. and K. Fujita. 2004. Potato marketing system and its changes in Bangladesh: From the perspective of village study in Comilla district. The Developing Economics XLII-1 (March): 63-94.

Shrestha, A.B., C.P. Wake, P.A. Mayewski and J.E. Dibb. 1999. Maximum temperature trends in the Himalaya and its vicinity: An analysis based on temperature records from Nepal for the period 1971-1994. Journal of Climate 12: 2775-87.

Singh, J.P., S. S. Lal, P.M. Govindakrishnan, V.K. Dua and S.K. Pandey. 2008. Climate change and potato production in India. Poster presented in Global Potato Conference-2008, New Delhi, December 09-12, 2008.

UNDP. 2008. Impacts of climate change on human development. Human Development Report 2007-2008. 